\title{
Concesiones de servicio público e Impuesto sobre Bienes Inmuebles (algunas reflexiones a la luz de la jurisprudencia y de la modificación del impuesto por la Ley 14/2000, de 29 de diciembre, de medidas fiscales, administrativas y del orden social)
}

\author{
Germán Fernández Farreres \\ Catedrático de Derecho Administrativo \\ Universidad Complutense de Madrid
}

\begin{abstract}
Sumario: I. INTRODUCCIÓN: LA REGULACIÓN INICIAL DE LA TRIBUTACIÓN POR EL IMPUESTO SOBRE BIENES INMUEBLES DE LOS QUE ESTÉN AFECTOS A CONCESIONES DE SERVICIO PÚBLICO (SUJETO PASIVO, HECHO IMPONIBLE Y EXENCIONES). II. LA DOCTRINA DE LA SENTENCIA DE LA SALA TERCERA DEL TRIBUNAL SUPREMO DE 25 DE SEPTIEMBRE DE 2000. III. LA MODIFICACIÓN DE LOS ARTÍCULOS 64.b) Y 65 DE LA LEY DE HACIENDAS LOCALES POR LA LEY 14/2000, DE 29 DE DICIEMBRE, DE MEDIDAS FISCALES, ADMINISTRATIVAS Y DEL ORDEN SOCIAL: SIGNIFICADO Y ALCANCE. 1. Modificación legislativa contra jurisprudentiam y confirmación de la interpretación judicial dada a la norma modificada. 2. Sobre la eficacia temporal de la modificación legislativa a la luz, en particular, de la doctrina de la STC 6/1983, de 4 de febrero. 3. Una referencia final a la repercusión del impuesto y a la incidencia que la supresión de la exención pueda tener en el equilibrio económico-financiero de las concesiones.
\end{abstract}

\section{INTRODUCCIÓN: LA REGULACIÓN INICIAL DE LA TRIBUTACIÓN POR EL IMPUESTO SOBRE BIENES INMUEBLES DE LOS QUE ESTÉN AFECTOS A CONCESIONES DE SERVICIO PÚBLICO (SUJETO PASIVO, HECHO IMPONIBLE Y EXENCIONES)}

La Ley 39/1988, de 28 de diciembre, reguladora de las Haciendas Locales (en adelante, LHL), ya desde su redacción originaria ha previsto que son sujetos pasivos del Impuesto sobre Bienes Inmuebles (en adelante, IBI), entre otras más,

«las personas físicas y jurídicas que sean [...] titulares de una concesión administrativa sobre bienes inmuebles gravados o sobre los servicios públicos a los que se hallen afectados» [art. 65.d)]. 
Complementariamente, el artículo 61 de la misma LHL dispone:

«El Impuesto sobre Bienes Inmuebles es un tributo directo de carácter real, cuyo hecho imponible está constituido por la propiedad de los bienes inmuebles de naturaleza rústica y urbana sitos en el respectivo término municipal o [...] por la titularidad [...] de una concesión administrativa sobre dichos bienes o sobre los servicios públicos a los que están afectados, y grava el valor de los referidos inmuebles.»

Así pues, los concesionarios de servicio público son sujetos pasivos del IBI en la medida en que a la concesión se encuentren afectados bienes inmuebles de naturaleza rústica y urbana. El elemento material de la relación jurídico-tributaria radica en la titularidad de unas concesiones administrativas que, sin recaer directamente sobre bienes inmuebles, necesitan de los mismos para prestar o desarrollar el servicio público cuya gestión ha sido concedida.

Ahora bien, presupuesto de esa configuración de los concesionarios de servicios públicos como sujetos pasivos es que los bienes inmuebles afectos al servicio público objeto de la concesión no sean de titularidad del concesionario ${ }^{1}$. Y es que, si lo fuesen, el concesionario bien pudiera considerarse sujeto pasivo, no ya por su condición de concesionario, sino por la de ser propietario de los mismos, ya que, según el apartado a) del mismo artículo 65 de la LHL,

«Son sujetos pasivos de este impuesto las personas físicas y jurídicas [...] que sean:

a) Propietarios de bienes inmuebles gravados sobre los que no recaigan derechos reales de usufructo o de superficie.»

En cualquier caso, tanto por una como por otra vía, los concesionarios de servicios públicos serían sujetos pasivos del IBI por razón de los bienes inmuebles vinculados a las concesiones. Sin embargo, que lo fuesen por uno u otro concepto tenía gran importancia dado el régimen de exenciones previsto.

\footnotetext{
${ }^{1}$ Queda al margen en este momento, por innecesaria a los efectos de la cuestión que se analiza, cualquier consideración acerca de si, desde la perspectiva misma del régimen concesional del servicio o, más propiamente, de la concesión de obra pública, resulta jurídicamente posible que los bienes inmuebles afectos a la misma, o cuya explotación constituye su objeto, sean de titularidad privada. Una cuestión, ciertamente compleja y difícil, sobre la que, entre los estudios más recientes, puede verse el análisis de F. J. JiMÉNEZ de Cisneros, Obras públicas e iniciativa privada, Madrid, Montecorvo, 1998, que, por lo demás, llega a la taxativa conclusión de que «[...] es perfectamente posible - al menos de un modo ideal - afirmar la existencia de una obra pública de titularidad privada, sujeta al tráfico jurídico-mercantil, y explotada por particulares, sin tener que considerarla como dominio público ni mucho menos como soporte de la prestación de un servicio público o administrativo» (p. 72).
} 


\author{
En efecto, el artículo 64.b) de la LHL, una vez más según su redacción \\ inicial, declaró:
}

«Gozarán de exención los siguientes bienes:

b) Los que sean propiedad de los municipios en que estén enclavados, afectos al uso o servicio públicos, así como los comunales propiedad de dichos municipios y los montes vecinales en mano común.»

Esta exención, que, más que como exención permanente de carácter subjetivo, quedó configurada como una exención permanente de carácter mixto ${ }^{2}$, obligaba a tener en cuenta si los bienes inmuebles afectos a la concesión de servicio público eran o no de titularidad municipal. Si no lo fuesen, sujeto pasivo sería el concesionario y la Administración o persona propietaria o titular de los bienes quedaría al margen de la relación jurídica tributaria ${ }^{3}$, sin que, además, por ser propietario de tales bienes otra Administración pública distinta de la municipal en la que se encontrasen enclavados pudiera aplicarse la exención. Por el contrario, si la titularidad fuese municipal, aun cuando sujeto pasivo seguiría siéndolo el concesionario, la exención regiría plenamente.

\footnotetext{
${ }^{2}$ Obsérvese que al quedar ceñida la exención a los bienes de dominio público municipal —es decir, los bienes de propiedad municipal destinados al uso o al servicio público: art. 79.3 de la Ley 7/1985, de abril, reguladora de las Bases del Régimen Local (en adelante, LBRL) - , al menos formalmente, quedan fuera de su ámbito de aplicación los bienes patrimoniales municipales, ya que la exención no se vincula en exclusiva al dato de la personalidad del titular del bien, sino que se toma en consideración la naturaleza intrínseca o el uso o destino dado al mismo. Con todo, tal como han advertido J. I. Rubio de Urquía y S. ARnal SuRia, La Ley reguladora de las Haciendas Locales, 2. ${ }^{a}$ ed., Madrid, Abella, 1996, t. I, p. 361, a pesar del tenor literal de la Ley, resulta verdaderamente arriesgado mantener a ultranza esa conclusión, pues, de una parte, «la intención original de los autores del Proyecto de Ley era la de declarar exentos a la totalidad de los bienes inmuebles del Municipio en el que estuvieran enclavados, cualquiera que fuere su naturaleza jurídica», y de la otra, «en el caso de no declarar exentos determinados bienes de los Municipios (los bienes patrimoniales), concurriría en estos últimos la doble condición de sujetos pasivos y sujetos activos del impuesto, circunstancia ésta que en el ámbito específico de la figura tributaria que se contempla constituye un verdadero absurdo».
}

Cuestión distinta es — así lo señalan los mismos autores - que la exención no pueda alcanzar «a los bienes inmuebles de los Organismos autónomos del Municipio en el que estén enclavados, ni a los de las Empresas o Sociedades mercantiles dependientes de dicho Municipio», al quedar ceñida la exención a los bienes inmuebles del Municipio considerado «como persona jurídica propia e independiente de la de sus Organismos autónomos y Sociedades mercantiles».

3 A la vista de que sujetos pasivos del impuesto son las personas titulares de concesiones administrativas sobre servicios públicos a los que estén afectos bienes inmuebles gravados por el impuesto [art. 65.d), inciso final, de la LHL], tienen razón J. I. Rubio de Urquía y S. S. Arnal Suria, Ley reguladora de las Haciendas Locales, op. cit., p. 381, cuando puntualizan que "parece evidente la intención del legislador de dejar completamente al margen de la relación jurídica tributaria del impuesto a la Entidad pública territorial titular del bien de uso público objeto de la concesión o del servicio al que esté adscrito el inmueble de que se trate». 
No obstante, lo que parecía evidente se cuestionó. Y así, algunos Ayuntamientos, basándose en que la exención no alcanzaba a esos bienes municipales cuando la gestión del servicio se hubiere encomendado a un particular ${ }^{4}$, procedieron a girar a los concesionarios las correspondientes liquidaciones. Se planteó, de este modo, un problema interpretativo que, al final, la jurisprudencia ha terminado por clarificar. Veamos en qué términos lo ha hecho.

\section{LA DOCTRINA DE LA SENTENCIA DE LA SALA TERCERA DEL TRIBUNAL SUPREMO DE 25 DE SEPTIEMBRE DE 2000}

La Sentencia de la Sala Tercera del Tribunal Supremo de 25 de septiembre de 2000, dictada en recurso de casación en interés de la ley, trae causa de un supuesto similar al de las concesiones de estaciones de autobuses que, a título de ejemplo, se han citado y su doctrina alcanza, con carácter general, a la tributación de los bienes inmuebles de propiedad municipal afectos a concesiones de servicio público. Dejando de lado la particularidad de que en el supuesto que diera lugar a la Sentencia se discutía el carácter de servicio público de los aparcamientos subterráneos —un dato, ciertamente, que en ningún caso es discutible cuando de concesiones de estaciones de autobuses se trata-, lo verdaderamente trascendente es la taxativa conclusión a la que se llega:

«[...] esta exención [la del art. 64.b) de la LHL], autónoma respecto de la que recoge el apartado a) del mismo precepto - $\mathrm{y}$, por ende, no supeditada a los particulares requisitos de ésta - únicamente exige, en cuanto aquí interesa, la pro-

\footnotetext{
${ }^{4}$ Entre otros supuestos, la explotación por particulares de estaciones de transporte por carretera (estaciones de autobuses) es un claro ejemplo de concesión de servicio a la que necesariamente se encuentran afectados bienes inmuebles. Esos bienes - dada la actual configuración normativa [arts. 127 y ss. de la Ley 16/1987, de 30 de julio, de Ordenación de los Transportes Terrestres (en adelante, LOTT) y 183 y ss. del Reglamento de 28 de septiembre de 1990] — no constituyen en sí mismos el objeto de la concesión, que no es otro que la explotación del servicio público de la estación en la que se concentran los servicios de salida, llegada y tránsito en el correspondiente municipio de los autobuses de transporte público regulares permanentes de viajeros de uso general por carretera (art. 127.1 de la LOTT); pero es claro que esos bienes están indisolublemente vinculados a la misma. Unos bienes, por lo demás, que suelen ser de titularidad municipal, sin perjuicio de que el hecho de que en algunos casos hayan podido ser cedidos gratuitamente, de acuerdo con lo dispuesto en el artículo 109.2 del Reglamento de Bienes de las Entidades Locales de 13 de junio de 1986 «a Entidades o Instituciones públicas para fines que redunden en beneficio de los habitantes del término municipal», les prive de esa titularidad, tal como se desprende de la propia institución de la cesión — distinta de la enajenación - y, en última instancia, de la propia previsión del artículo 111.3 del mismo Reglamento de Bienes: «los bienes cedidos revertirán, en su caso, al Patrimonio de la Entidad cedente con todas sus pertenencias y accesiones».
} 
piedad municipal y el destino de los bienes de que se trate al uso o servicio públicos» (F.D. 3. $\left.{ }^{\circ}\right)$.

Y más adelante, en el mismo fundamento jurídico, se añade:

$\ll[\ldots]$ tan pronto se comprenda que la propiedad municipal de los bienes y su adscripción a un servicio público, que en realidad han configurado siempre el concepto de bienes de servicio público municipal, como se ha visto, no es incompatible con el otorgamiento de aprovechamiento de los mismos y con el pago por ese aprovechamiento de cánones, tarifas o incluso de cantidades alzadas, como ocurre en el supuesto aquí enjuiciado, también tradicionalmente previsto en el contenido de la concesión - arts. 115.6. ${ }^{\mathrm{a}}$ del Reglamento de Servicios precitado y 156.1 del Texto Refundido de la Ley de Contratos de las Administraciones Públicas, igualmente citado - . Por lo demás, ya se ha anticipado la imposibilidad de extrapolar a la exención aquí enjuiciada las exigencias de uso o aprovechamiento general y gratuito que la exención del ap. a) del art. 64 de la Ley de Haciendas Locales impone, para reconocer la exención, a las carreteras, caminos, restantes vías terrestres y a los bienes de dominio público marítimo-terrestre e hidráulico, según la redacción recibida de la Ley 13/1996, de 30 de diciembre, y que cuadra perfectamente con su naturaleza de bienes de dominio público, subespecie de uso público - dominio natural, en la antigua denominación-, pero que sería difícilmente exigible en bienes afectos a un servicio público que, aun prestado con los caracteres de generalidad antes expuestos, suele suponer la retribución del servicio de que se trate sin por ello obstar a la virtualidad de una exención del IBI fundada en esa particular condición.»

Por tanto, los concesionarios de un servicio público quedan exentos del IBI cuando los bienes inmuebles adscritos a la concesión sean bienes del Municipio en el que estén enclavados. Y por eso mismo puede afirmarse con seguridad que las impugnaciones de las liquidaciones - tanto las giradas a los concesionarios de aparcamientos subterráneos, como a los de estaciones de autobuses y a cualesquiera otros que gestionen servicios públicos - que aún se encuentren pendientes de resolución, irremisiblemente habrán de ser estimadas por ser dichas liquidaciones nulas de pleno derecho.

La cuestión, por tanto, quedaba definitivamente aclarada y resuelta. Pero la reacción del legislador no se ha hecho esperar. 


\section{LA MODIFICACIÓN DE LOS ARTÍCULOS 64.b) Y 65 DE LA LEY DE HACIENDAS LOCALES POR LA LEY 14/2000, DE 29 DE DICIEMBRE, DE MEDIDAS FISCALES, ADMINISTRATIVAS Y DEL ORDEN SOCIAL: SIGNIFICADO Y ALCANCE}

Que el artículo 64.b) de la LHL había establecido la exención en los términos que ha confirmado la doctrina sentada por la Sala Tercera del Tribunal Supremo, es lo que explica la reciente modificación del señalado precepto y la del artículo 65 de la misma Ley por el artículo 22 de la Ley 14/2000, de 29 de diciembre, de medidas fiscales, administrativas y del orden social.

Reconocida la efectividad de una exención que no debió cuestionarse - lo que, además, habría evitado unas controversias judiciales absolutamente innecesarias - , la respuesta ha sido la modificación del presupuesto de dicha exención. Una respuesta legislativa en oposición frontal a la comentada doctrina legal, que, por ello mismo, viene a admitir implícita, pero inequívocamente, que los bienes inmuebles municipales afectos a concesiones de servicio público gozaban de exención en el IBI. De manera que, con la nueva redacción dada al artículo 64.b), en el futuro no habrá en tales casos exención ninguna. Dice así la nueva redacción:

«Gozarán de exención los siguientes bienes:

b) Los que sean propiedad de los Municipios en que estén enclavados afectos al uso o servicio público, salvo que sobre ellos o sobre el servicio público al que se hallen afectados recaiga una concesión administrativa u otra forma de gestión indirecta, así como los comunales propiedad de los mismos y los montes vecinales en mano común.»

La reforma se ha extendido también al artículo 65. El apartado a) de su número 1 establece ahora que son sujetos pasivos del impuesto las personas físicas y jurídicas y las Entidades a que se refiere el artículo 33 de la Ley General Tributaria, que sean:

«Propietarios de bienes inmuebles sobre los que no recaigan derechos reales de usufructo, superficie o una concesión administrativa.»

Se añade, en consecuencia, a ese apartado a) una mención expresa - antes inexistente - a la concesión administrativa, a fin de guardar plena coherencia con la condición - ya prevista antes de la modificaciónde sujetos pasivos del impuesto de los titulares de concesiones administrativas sobre bienes inmuebles o sobre servicios públicos a los que se ha- 
llen afectados, sean o no de propiedad municipal (al igual, por lo demás, que los usufructuarios o los titulares de un derecho real de superficie).

Por último, se incorpora un nuevo número 2 al mismo artículo 65 , cuyo tenor literal es el siguiente:

«Lo dispuesto en el apartado anterior será de aplicación sin perjuicio de la facultad del sujeto pasivo de repercutir el impuesto conforme a las normas de Derecho común.»

Hasta aquí la nueva regulación legal. Una reforma que propicia las consideraciones siguientes:

\section{Modificación legislativa contra jurisprudentiam y confirmación de la interpretación judicial dada a la norma modificada}

La relación causa-efecto entre la doctrina legal fijada por la Sentencia de la Sala Tercera del Tribunal Supremo de 25 de septiembre de 2000 y la reforma del artículo 64.b) de la LHL parece indiscutible. La Exposición de Motivos de la Ley 14/2000, de 29 de diciembre, de manera genérica reconoce que «las disposiciones tributarias contenidas en el Título I de esta Ley vienen exigidas, en general, por tres circunstancias»: concretamente, por «imperativo legal», por «razones de tipo técnico, derivadas de la experiencia de aplicación de las normas tributarias por la Administración y los contribuyentes, así como del impacto que la jurisprudencia y la doctrina van generando en la normativa tributaria»y, finalmente, por la búsqueda de «incentivar determinadas actuaciones». Y a partir de esas tres razones básicas, según cada caso, se explicita el motivo de la reforma.

Sin embargo, para nada se alude a la reforma de la LHL — un silencio que no deja de ser significativo-, si bien parece evidente que la misma no responde sino a ese «impacto que la jurisprudencia y la doctrina van generando en la normativa tributaria». Lo que sucede es que, en el supuesto que se analiza, la reforma no ha estado al servicio de ajustar la Ley a la jurisprudencia y doctrina, sino justamente todo lo contrario. La reforma es una reforma contra jurisprudentiam, guiada por la finalidad de evitar en el futuro sus consecuencias y efectos. Un dato éste que, en sí mismo, ciertamente, no permite imputar en estrictos términos jurídicos tacha alguna a la reforma, pero que muestra bien a las claras el sentido y finalidad de la misma, claramente sesgados por un mero afán recaudatorio, con olvido de otras exigencias no menos importantes ${ }^{5}$, y marcada, desde lue-

${ }^{5}$ Como ha dicho Eloy GARCíA, «Estado fiscal y política municipal de transportes: acerca de la exigibilidad del Impuesto sobre Bienes Inmuebles a los concesionarios de estaciones de autobuses de 
go, por la urgencia y, en cierto modo, la improvisación. La propia utilización del cuestionado instrumento de la Ley de acompañamiento a los Presupuestos Generales del Estado no deja lugar a dudas ${ }^{6}$.

En todo caso, la reforma viene a ratificar, como ya he anticipado, que, con anterioridad a la misma, los bienes inmuebles propiedad de los Municipios afectados a concesiones de servicio público gozaban de exención. El contenido de la modificación legal lo avala plenamente. Si no hubieran gozado de exención, no habría habido cambio. Un cambio dirigido precisamente a poner fin a esa situación. Ninguna incidencia, por tanto, puede tener sobre los ejercicios anteriores a su entrada en vigor, en los que la exención ha regido con toda plenitud.

\section{Sobre la eficacia temporal de la modificación legislativa a la luz, en particular, de la doctrina de la STC 6/1983, de 4 de febrero}

Ahora bien, que la Ley de reforma no tenga en estrictos términos efectos retroactivos, por cuanto la eliminación de la exención no alcanza a ejercicios anteriores a su entrada en vigor, no significa que, a partir de ese momento, no sea aplicable a cualesquiera concesiones de servicio preexistentes ${ }^{7}$.

En efecto, los concesionarios de servicio con bienes inmuebles municipales vinculados al servicio, tras la Ley 14/2000, de 29 de diciembre,

titularidad pública», en Revista del Instituto de Estudios Económicos, n. ${ }^{\circ} 4$ (2000), p. 243, «[...] no son las políticas movidas por el simple afán recaudatorio las que deben guiar la acción del Ministerio de Hacienda. La idea de Estado de Derecho y nuestro concepto de lo público, a cuya definición, como ya vimos, contribuyó, entre otros, Schumpeter, exige que el hecho imponible sea delimitado con precisión con carácter previo, aplicado con neutralidad por una Administración que no puede actuar, a la vez, como juez y parte, y destinado a obtener beneficios para la colectividad que van mucho más allá del mero afán recaudatorio».

${ }^{6}$ Por todos, sobre este tipo de ley, vid. E. García de EnTERría, Justicia y seguridad jurídica en un mundo de leyes desbocadas, Madrid, 1999, en especial, pp. 75 ss.

7 Aunque no deja de ser verdad, como ha señalado F. LóPEz MENUdo, «El principio de irretroactividad de las normas en la jurisprudencia constitucional», en vol. col. Estudios sobre la Constitución Española. Homenaje al profesor E. García de Enterría, Madrid, Civitas, 1991, t. I, p. 458, que, «[...] generalmente, toda nueva disposición que incide sobre situaciones y relaciones jurídicas en curso tiene en mayor o menor medida un cierto efecto retroactivo, produciendo en los destinatarios una alteración de sus anteriores posiciones jurídicas: se quiere decir, en suma, que es lo normal y no lo excepcional que las nuevas disposiciones produzcan un cierto impacto sobre el tejido de los estados jurídicos vivos». De manera que, como el mismo autor apostilla, «en puridad, toda la cuestión se reduciría en fijar el punto en que la retroactividad deja de ser un efecto legítimo de la norma que los destinatarios deben soportar, para convertirse en un efecto patológico, jurídicamente reprochable». 
dejan de estar exentos, sin que pueda pretenderse excepcionar esa fundamental consecuencia al amparo del principio de irretroactividad de las disposiciones no favorables que sanciona el artículo 9.3 de la Constitución. La excepción únicamente habría sido posible si la reforma hubiera venido acompañada de una disposición transitoria que modulara en el tiempo la aplicabilidad del nuevo régimen de no exención a las concesiones preexistentes. Pero, por razonable que pudiera parecer, el legislador, a diferencia de cómo suele actuar en otras ocasiones, no ha creído oportuno establecer transitoriedad alguna ${ }^{8}$. De manera que el hecho de que las concesiones preexistentes dejen de gozar de la exención no es sino resultado de la falta de transitoriedad en el despliegue pleno de la eficacia de la Ley, que queda directamente vinculado sin más al hecho de su entrada en vigor.

Más aún. De inmediato hay que añadir que, aun cuando no fuera así, tampoco podría ponerse en cuestión la constitucionalidad de la Ley. La posición mantenida por el Tribunal Constitucional al enjuiciar la constitucionalidad de la Disposición Transitoria 2. ${ }^{\text {a }}$, apartado b), del Real Decreto-Ley de 20 de julio de 1979, sobre Medidas Urgentes de Financiación de las Corporaciones Locales, resulta a este respecto definitiva. Conviene, por ello, recordar la doctrina de la STC 6/1983, de 4 de febrero, que desestimó el recurso de inconstitucionalidad planteado contra dicha norma legal.

La norma dispuso que la reducción del 90 por 100 de la base imponible, establecida en el artículo 12.6. ${ }^{\circ}$ del Texto Refundido de la Contribución Urbana a favor de las viviendas de protección oficial, se transformaría a partir del 1 de enero de 1980 en una bonificación del 50 por 100 . De esta forma, los propietarios de viviendas de protección oficial cuya construcción hubiera sido terminada con anterioridad a dicha fecha vieron reducida la cuantía de la bonificación — que se les había otorgado por un plazo de veinte años - por el plazo de tiempo que restase hasta completar esos veinte años. Asimismo, para las viviendas construidas a partir del 1 de enero de 1980, la bonificación de la base imponible de la Contribución Urbana quedó fijada en el 50 por 100 y por un plazo de tres años, a contar desde la terminación de la construcción. Previsión ésta que, desde

\footnotetext{
${ }^{8}$ Baste recordar, por ejemplo, que la Disposición Transitoria 2.⒉ párrafo $1 .^{\circ}$, de la LHL estableció un régimen transitorio para los beneficios fiscales, según el cual «quienes a la fecha de comienzo de aplicación del Impuesto sobre Bienes Inmuebles (1 de enero de 1990) gocen de cualquier clase de beneficio fiscal en la Contribución Territorial Rústica o en la Contribución Territorial Urbana, continuarán disfrutando de los mismos en el impuesto citado en primer lugar, hasta la fecha de su extinción y, si no tuvieran término de disfrute, hasta el 31 de diciembre de 1992, inclusive».
} 
un punto de vista material, ningún reparo suscitó, por cuanto se trataba de una previsión de futuro que no tenía incidencia alguna en relaciones jurídicas previamente constituidas.

Las dificultades surgían respecto de la reducción de los beneficios fiscales concedidos con anterioridad a la entrada en vigor del Real Decreto-Ley y por ese plazo de veinte años, a contar desde la fecha de su otorgamiento; es decir, desde la terminación de la edificación y comprobación administrativa de que la vivienda se adecuaba a la normativa reguladora de las características que habían de tener las viviendas de protección social ${ }^{9}$. La previsión normativa, con rango y valor de ley, incidía y afectaba directamente a situaciones jurídicas preexistentes, provocando la modificación sobrevenida de las condiciones con que en su momento fueron otorgados los referidos beneficios fiscales.

Pues bien, a pesar de que, en principio, esa bonificación del 90 por 100 de la base imponible de la Contribución Urbana por un determinado plazo de tiempo constituía un típico ejemplo de utilización del beneficio tributario con una finalidad extrafiscal de fomento e incentivo de la construcción de viviendas de determinadas características y precios ${ }^{10}$, el Tri-

\footnotetext{
${ }^{9}$ Fácilmente se aprecia, por tanto, que ni siquiera ese es el supuesto de la eliminación de la exención a favor de los bienes inmuebles municipales afectos a concesiones de servicios públicos, ya que, a diferencia de la bonificación fiscal de las viviendas de protección oficial, la referida exención no ha sido objeto de ningún otorgamiento singular y específico, ni por un plazo determinado. Y es que, mientras que la bonificación de las viviendas de protección oficial respondía claramente a la utilización del beneficio fiscal con un fin de fomento, la exención de los bienes inmuebles municipales afectos a concesiones de servicios públicos no se previó con esa finalidad. A los beneficios tributarios otorgados con fines extrafiscales - en concreto, con fines de fomento e incentivo, lo que determina el surgimiento de una relación jurídica paralela, pero diferenciable de la estricta relación jurídico-tributaria en la que se incardina la exención o la bonificación tributaria-, ya me he referido en otras ocasiones: vid., con carácter general, G. FERNÁNDEZ FARRERES, La subvención: concepto y régimen jurídico, Madrid, IEF, 1983, pp. 112 ss., y más específicamente, al hilo precisamente de la STC 6/1983, de 4 de febrero, en «De nuevo sobre la subvención y su régimen jurídico en el Derecho español», Revista de Administración Pública, n. ${ }^{\circ} 113$ (1987), pp. 39 ss. Sin perjuicio de la amplísima bibliografía existente, vid., asimismo, el trabajo de G. CASADo Ollero, «Los fines no fiscales de los tributos», en vol. col. Comentarios a la Ley General Tributaria y líneas para su reforma. Libro homenaje a F. Sainz de Bujanda, Madrid, IEF, pp. 103 ss.
}

${ }^{10} \mathrm{Al}$ igual que sucede con las subvenciones $\mathrm{y}$, en general, cualesquiera ayudas económicas otorgadas afectadamente, para beneficiarse de la bonificación era preciso la observancia de determinadas exigencias y requisitos, es decir, el cumplimiento de una carga jurídica u obligación en sentido genérico. Como ya indiqué en mi trabajo «De nuevo sobre la subvención...», cit., p. 56, «[...] "a cambio", podría decirse gráficamente, aunque en un sentido atécnico, de unas específicas ventajas fiscales por un plazo de tiempo determinado, el Estado persigue estimular la construcción y adquisición en propiedad de viviendas de unas determinadas características, con lo que, en principio, todo parece indicar que se articula el típico esquema relacional al que se ajusta el otorgamiento de subvenciones y demás ayudas afectadas. Se entablaría una relación jurídica de carácter unilateral, de la que nacería un derecho subjetivo a favor del titular de la vivienda de protección oficial correlativo a 
bunal Constitucional llegó a la conclusión de que el derecho a la exención o a la bonificación tributaria es un elemento de la relación jurídico-obligacional no integrable en el patrimonio del sujeto pasivo y no constitutivo, por ello, de un derecho subjetivo propiamente dicho. Y aún añadió que la irretroactividad amparada en el artículo 9.3 de la Constitución se refiere exclusivamente a las disposiciones sancionadoras no favorables o restrictivas de derechos individuales, por lo que tampoco es reconducible a dicha previsión constitucional la norma que reduce la cuantía de una bonificación otorgada por un determinado plazo. En el FJ 2 de la misma Sentencia se puede leer:

«Las normas que establecen exenciones o reducciones tributarias crean ciertamente situaciones jurídicas individualizadas en favor de los beneficiados. Puede discutirse doctrinalmente cuál es la naturaleza del poder jurídico que se atribuye a los sujetos, a los que la norma previene que le sea aplicada la exención o la bonificación, pero no cabe duda que, en definitiva, tal poder consiste en no satisfacer un determinado tributo o en satisfacerlo en una cuantía menor que la prevista con carácter general. Algún autorizado sector doctrinal ha sostenido que en la exención de carácter general existe un derecho subjetivo al disfrute de la misma, que no puede ser suprimido ni suspendido durante su tiempo de vigencia, de manera tal que la derogación de las normas en que la exención hubiera sido concedida no puede acarrear la pérdida de ese derecho, ni puede éste tampoco verse afectado por otras normas posteriores que supriman explícitamente las exenciones, porque en tal caso estaríamos en un supuesto de violación de derechos tributarios adquiridos. Sin embargo, a nuestro juicio, es más correcto entender que el llamado derecho a la exención o a la bonificación tributaria es simplemente un elemento de la relación jurídica obligacional, que liga a la Administración y al contribuyente y que, en el caso de la contribución territorial, no integra el derecho de propiedad, el de usufructo o el derecho real concreto que sea objeto de la contribución. El objeto de la exención - no pagar o pagar una cantidad inferior a la prevista con carácter general - es distinto del objeto sobre el que recae el derecho real. Por ello, no puede hablarse en puridad de un auténtico derecho a la bonificación tributaria o al mantenimiento del régimen jurídico-tributario de bonificación, que puede entenderse incorporado al patrimonio de los titulares del dominio — en nuestro caso, a la propiedad de viviendas de protección oficial—y del que éstos pueden entenderse privados en virtud de una norma como el Real Decreto-Ley $11 / 1979$, por lo cual se muestra como totalmente infundada la eventual idea de una violación del artículo 33 de la Constitución.»

La conclusión es que no puede hablarse en rigurosos términos de un derecho subjetivo al mantenimiento del régimen jurídico-tributario de la bonificación. La sentencia constitucional conjuga al respecto diversas consideraciones, pero el punto central de toda la argumentación radica en que la exención no pasa de ser sino un elemento de la relación jurídica

una serie de cargas que, evidentemente, no pesan sobre el propietario de una vivienda de otras características. Circunstancia que impediría, por tanto, cualquier modificación de los términos de dicha relación si la misma no fuera acompañada de la correspondiente indemnización». 
obligacional que se integra en las normas delimitadoras del presupuesto de hecho del impuesto, razón por la cual difícilmente puede hablarse de un derecho a la exención o a la bonificación que forme parte del patrimonio del contribuyente ${ }^{11}$.

Aunque esta doctrina adopta un punto de vista excesivamente amplio y general, desconociendo la diversa instrumentalidad con que pueden ser previstas y otorgadas las exenciones y demás beneficios tributarios ${ }^{12}$, su

${ }^{11}$ Negación, por tanto, de que exista un derecho adquirido. Pero es que, además, aun cuando se prescindiese de este dato, no puede olvidarse que el límite constitucional a la retroactividad de la ley queda ceñido a que se trate de «disposiciones sancionadoras no favorables» 0 «restrictivas de derechos individuales», y la propia jurisprudencia constitucional ha rechazado, desde el primer momento, que esos «derechos individuales» que se refieren en el artículo 9.3 de la Constitución sean cualesquiera «derechos adquiridos». La STC 27/1981, de 20 de julio, ya lo señaló con absoluta claridad:

«Desde el punto de vista de la constitucionalidad, debemos rehuir cualquier intento de aprehender la huidiza teoría de los derechos adquiridos, porque la Constitución no emplea la expresión "derechos adquiridos", y es de suponer que los constituyentes la soslayaron, no por modo casual, sino porque la defensa a ultranza de los derechos adquiridos no casa con la filosofía de la Constitución, no responde a exigencias acordes con el Estado de Derecho que proclama el artículo 1 de la Constitución, fundamentalmente, porque esa teoría de los derechos adquiridos, que obliga a la Administración y a los tribunales cuando examinan la legalidad de los actos de la Administración, no concierne al Legislativo ni al Tribunal Constitucional cuando procede a la función de defensa del ordenamiento, como intérprete de la Constitución. Cuando se trata de la defensa del ordenamiento constitucional, hemos de tener en cuenta que el concepto de "derecho individual" no puede confundirse con el ius quaesitum; el 9.3 - en todo o en parte - alude a los derechos fundamentales del Título I [...]».

Y con posterioridad, refiriéndose, además, expresamente a la legislación tributaria retroactiva, la STC 126/1987, de 16 de julio — cuya doctrina se reitera por la STC 156/1987, de 14 de octubre-, recuerda que

«no existe una prohibición constitucional de la legislación tributaria retroactiva. La prohibición que el 9.3 establece tan sólo para las "disposiciones sancionadoras no favorables" y para las "restrictivas de derechos individuales" se extendía también a las fiscales en el Anteproyecto de la Constitución, y la inclusión de las mismas se mantuvo en el Informe de la Ponencia, pero desapareció en el Dictamen de la Comisión de Asuntos Constitucionales [...]».

12 Así lo advertí ya en mi trabajo «De nuevo sobre la subvención...», cit., pp. 58 ss., pues, sin discutir que la exención no pasa de ser sino un elemento más de la relación jurídico-obligacional y, por tanto, sometida como regla a la libre disponibilidad del legislador, no puede desconocerse que esa exención puede tener su origen y fundamento en consideraciones de diversa índole, ya sean de estricta justicia tributaria o, por el contrario, de orden extrafiscal, sucediendo, en este último supuesto, que, junto a la relación jurídica obligacional entre Administración y contribuyente, coexiste en última instancia - y se proyecta sobre la misma - otra relación jurídica, la surgida del acto de otorgamiento del beneficio tributario con arreglo a la legislación no necesariamente tributaria que lo haya previsto y con arreglo a los requisitos, condiciones y demás circunstancias que correspondan. Por eso, la afirmación genérica de que la exención no pasa de ser un elemento más de la relación jurídica tributaria no parece que pueda justificar plenamente la subsiguiente afirmación de que no existe derecho subjetivo alguno en el beneficiario a que la exención siga aplicándosele durante el plazo y en la cuantía en que le fuera concedida. 
proyección a un supuesto como el de la supresión en el IBI de la exención de que han gozado los bienes inmuebles municipales afectos a concesiones de servicio público conduce a descartar que con la misma se hayan afectado retroactivamente derechos adquiridos de los concesionarios-sujetos pasivos del impuesto.

En definitiva, no parece que pueda decirse que la eliminación de la exención haya transgredido el límite de la irretroactividad que sanciona el artículo 9.3 de la Constitución. Y ello por un triple orden de consideraciones, directamente resultantes de la jurisprudencia constitucional: primero, porque la supresión no tiene alcance retroactivo ${ }^{13}$; segundo, porque, aunque se admitiera hipotéticamente ese alcance retroactivo, no hay derecho subjetivo al mantenimiento del régimen jurídico-tributario de la exención, dado que ésta no pasa de ser un elemento más de la relación jurídica obligacional tributaria, en los términos ya señalados; y tercero, porque ni siquiera los derechos adquiridos —al menos, cualquier derecho adquirido - operan como límite a la retroactividad de la Ley, sin que, además, y en particular, el artículo 9.3 de la Constitución haya garantizado la irretroactividad de las leyes fiscales.

\footnotetext{
Ahora bien, como ya he dicho, la exención que se estableció a favor de los bienes inmuebles municipales afectos a concesiones de servicio público no parece que respondiese a esa lógica, por lo que debe quedar descartado el planteamiento que acabo de referir.

${ }^{13}$ Razón por la cual — vale la pena insistir en ello-, hasta la entrada en vigor de la Ley de supresión, debe reconocerse plenamente el derecho a la exención.

Por otra parte, dando entrada a la doctrina de los «grados de la retroactividad» (sobre la misma, vid. F. LóPez Menudo, El principio de irretroactividad en las normas jurídico-administrativas, Sevilla, IGO, 1982, pp. 48 y ss. y su posterior trabajo «El principio de irretroactividad de las normas en la jurisprudencia constitucional», cit., pp. 501 ss.), la misma STC 6/1983, de 4 de febrero, ni siquiera por relación a esa reducción de las bonificaciones otorgadas con un fin de fomento y de incentivo y vinculadas a la adquisición de determinado tipo de viviendas - lo que suponía que los adquirentes asumieran ciertas cargas jurídicas, como «contrapartida», pues, del beneficio fiscal一, ni siquiera, digo, admitió — por discutible que sea — que existiese una retroactividad contraria al artículo 9.3 de la Constitución:
}

«Los preceptos cuestionados regulan, en materia de viviendas de protección oficial, los efectos de las situaciones tributarias que se producen con posterioridad al 1 de enero de 1980, es decir, con posterioridad a su entrada en vigor. No posee por tanto un efecto retroactivo pleno o de grado máximo ni tampoco la retroactividad llamada de grado medio, que incide sobre efectos jurídicos ya producidos y todavía no agotados o consumados de las situaciones anteriores que perviven tras el cambio legislativo. Por ello, no es posible apreciar vulneración de la norma formulada en el art. 9.3 de la Constitución.» 


\section{Una referencia final a la repercusión del impuesto y a la incidencia que la supresión de la exención pueda tener en el equilibrio económico-financiero de las concesiones}

Dos últimas cuestiones quedan por comentar. La primera se vincula directamente a la nueva previsión incorporada al artículo 65.2 de la LHL. Dice así:

«Lo dispuesto en el apartado anterior será de aplicación sin perjuicio de la facultad del sujeto pasivo de repercutir el impuesto conforme a las normas de Derecho común.»

Expresamente se reconoce que los sujetos pasivos podrán, en su caso, repercutir el impuesto «conforme a las normas de Derecho común». Esa posibilidad de repercutir ya se reconoció, por ejemplo, en materia de arrendamientos por la Ley 29/1994, de 24 de noviembre, de Arrendamientos Urbanos, por cuanto su Disposición Transitoria Segunda, en la letra c), punto 10.2, establece que el arrendador (en los casos de arrendamientos de viviendas anteriores al 9 de mayo de 1985) «podrá exigir del arrendatario el total importe de la cuota del Impuesto sobre Bienes Inmuebles que corresponda al inmueble arrendado». Ahora, y con carácter general, en la propia regulación del IBI se deja a salvo la facultad del sujeto pasivo de repercutir el impuesto.

Pues bien, ¿el concesionario del servicio público-sujeto pasivo del impuesto podrá repercutir la correspondiente cuota a la Administración titular de ese servicio? Desde luego, no hay norma alguna específica que así lo prevea, por lo que, en principio, parece que la respuesta tiene que ser negativa. La traslación jurídica de la cuota tributaria, como es bien sabido, opera como consecuencia de la actuación de un derecho que otorga la Ley, de manera que no hay verdadera traslación — verdadera repercusión- cuando el título en virtud del cual se «transfiere» la cuota es el contrato. La facultad del sujeto pasivo que el artículo 65.2 de la LHL deja a salvo es, por eso mismo, la resultante de un derecho legal, de modo que ese derecho sólo será exigible si la correspondiente norma lo ha reconocido. Y todo esto, claro es, sin que el sujeto obligado a sufrir el traslado de la cuota o repercusión del impuesto llegue a entablar relación alguna con el acreedor de la deuda tributaria o sujeto activo del impuesto, es decir, con la correspondiente Administración tributaria municipal.

En la regulación de las diversas formas de gestión indirecta de los servicios prevista en el artículo 85 de la LBRL, nada se dice al respecto. Tampoco en la legislación de contratos de las Administraciones Públicas 
(arts. 154 y ss. del Texto Refundido de la Ley de Contratos de las Administraciones Públicas, aprobado por Real Decreto Legislativo 2/2000, de 16 de junio), ni, de manera ya particularizada, en la regulación de la gestión indirecta de los singulares servicios (por ejemplo, para las estaciones de transporte por carretera, arts. 127 a 132 de la LOTT y 183 a 187 del Reglamento de 28 de septiembre de 1990). Queda confirmado, pues, que el concesionario-sujeto pasivo del IBI no ostenta derecho a trasladar la cuota del impuesto a la Administración concedente del servicio.

No obstante - y es la segunda de las cuestiones - la supresión de la exención puede incidir en el régimen económico-financiero de unas concesiones que, cuando fueron otorgadas, con arreglo al marco normativo vigente estaban exentas del impuesto local sobre bienes inmuebles. Una exención que, lógicamente, se tendría en cuenta en la elaboración del oportuno estudio económico de la explotación que sirvió de fundamento a la propuesta y establecimiento de las correspondientes tarifas por la prestación del servicio. En consecuencia, aun cuando éste se gestione a riesgo y ventura del concesionario [con carácter general, art. 156.a) del Texto Refundido de la Ley de Contratos de las Administraciones Públicas], no cabe descartar que, de producirse - a resultas de la supresión de la exención - una alteración significativa del equilibrio económico-financiero de la concesión, pueda instarse la revisión de dichas tarifas ${ }^{14}$.

Más problemático será que de no accederse a esa revisión tarifaria la Administración titular del servicio concedido venga obligada a compensar económicamente al concesionario mediante una subvención o mediante la reducción del canon concesional, si éste se hubiere previsto. Es evidente que si la alteración del equilibrio económico-financiero se debe al ejercicio por la Administración del ius variandi para modificar unilateralmente, por razones de interés público, las características del servicio

\footnotetext{
${ }^{14}$ Debe recordarse que el equilibrio económico-financiero de la concesión debe mantenerse a todo lo largo del plazo concesional. Por ello, el artículo 152, párrafo $3 .^{\circ}$, del Reglamento de Servicios de las Corporaciones Locales ya previó que la revisión de las tarifas se producirá «siempre que se produjese un desequilibrio en la economía de la empresa o de la concesión, por circunstancias independientes a la buena gestión de una u otro». Con todo, esa garantía del equilibrio económico-financiero no puede desvincularse de la causa concreta determinante de su alteración o quiebra, porque, frente a lo que pudiera parecer, la referida garantía no supone que el concesionario deba ser en todos los casos compensado íntegramente por la pérdida de beneficio o, incluso, por los déficit que pueda experimentar. Cuestión esta fundamental para tratar de situar en su justa medida el juego del principio de que la gestión del servicio lo será a riesgo y ventura del concesionario. Y cuestión también decisiva para concretar el alcance del concepto «margen normal de beneficio industrial»o los «supuestos económicos que fueron considerados como básicos en la adjudicación del contrato».
} 
concedido o las tarifas que han de ser abonadas por los usuarios, la propia Administración deberá recomponerlo en su integridad ${ }^{15}$.

Sin embargo, distinto será que esa alteración se deba a la concurrencia de circunstancias sobrevenidas e imprevisibles, es decir, a hechos totalmente ajenos a la actuación de la Administración. En este caso, la incidencia de los diversos factores económicos concurrentes en la gestión empresarial pueden producir un desequilibrio que determine que el concesionario no alcance el beneficio previsto o, incluso, que se genere una pérdida económica. Con todo, lo relevante es que esa quiebra de la economía de la concesión nada tiene que ver con la alteración debida a la modificación unilateral del contrato por la Administración, por lo que las consecuencias en orden a la garantía del equilibrio económico-financiero tampoco pueden ser las mismas.

Por de pronto, la legislación estatal de contratos de las Administraciones Públicas no ha terminado por sancionar expresamente la preservación del contrato concesional frente a las alteraciones de su régimen económico por circunstancias sobrevenidas e imprevisibles ${ }^{16}$. Una garantía del empresario-concesionario ante el riesgo imprevisible que, dado el silencio legal, sólo encuentra sustento en las previsiones de los artículos 127.2 y concordantes del viejo Reglamento de Servicios de las Corporaciones Locales, de 17 de junio de $1955^{17}$. Pero, aun prescindiendo de esta circunstancia, la modulación del principio de riesgo y ventura no parece que

15 Que la gestión del concesionario lo sea «a su riesgo y ventura» no significa, desde luego, que la Administración concedente del servicio no deba compensarle íntegramente por los perjuicios que resulten del ejercicio de ese ius variandi. Como ha puntualizado el TS [por ejemplo, Sentencia de 24 de diciembre de 1997 (ar. 9622)], el principio de riesgo y ventura en la contratación administrativa «[...] no incluye las alteraciones que sean debidas al ejercicio por la Administración de su ius variandi, que han de ser debidamente indemnizadas para mantener el equilibrio de las prestaciones originariamente pactadas». Por eso, la modificación unilateral del contrato de concesión determina que el contratista-concesionario haya de ser resarcido por los perjuicios económicos que resulten de la modificación, tal como, por lo demás, establece el artículo 163.2 del Texto Refundido de la Ley de Contratos de las Administraciones Públicas. Una compensación, en fin, que ha de ser íntegra [STS de 2 de julio de 1979 (ar. 2866)], incluyendo el daño emergente y el lucro cesante [entre otras muchas más, SSTS de 23 de febrero de 1979 (ar. 978), 30 de diciembre de 1983 (ar. 6843), 30 de abril de 1981 (ar. 1841), etc.].

${ }^{16}$ Como ya advirtiera J. M. BAÑo LEÓN, «El contrato de gestión de servicios públicos», en vol. col. Derecho de los Contratos Públicos, Barcelona, Praxis, 1995, p. 686, refiriéndose a la Ley de Contratos de las Administraciones Públicas de 18 de mayo de 1995, «es claro que el legislador ha renunciado, contra el criterio propuesto por un amplio sector doctrinal, a generalizar el principio de cooperación económica frente al riesgo imprevisible, entendido éste como un hecho o conjunto de hechos ajenos al contrato, no previsibles, y que altera previamente la economía del contrato».

17 Unas previsiones, además, que, en el mejor de los casos, sólo son formalmente aplicables a los contratos concesionales que celebren las Corporaciones locales. 
pueda materializarse en una compensación integral de los perjuicios, sino que, a lo sumo, será una compensación parcial. Así se mantuvo en la STS de 11 de junio de 1978, al entender que el derecho del concesionario sólo alcanza a la compensación total de perjuicios en el caso de modificaciones ordenadas por la Administración, no en el de circunstancias imprevisibles, en el que bastará, si fuere necesario, con una subvención suficiente y adecuada para eliminar el riesgo de ruina de la empresa ${ }^{18}$. Otras Sentencias posteriores [por ejemplo, SSTS de 21 de octubre de 1980 (ar. 4005), de 23 de diciembre de 1981 (ar. 5295), de 14 de marzo de 1985 (ar. 1592), de 9 de octubre de 1987 (ar. 8326), o de 17 de julio de 1991 (ar. 6171)], se han orientado en la misma dirección ${ }^{19}$, y en la doctrina tampoco han faltado, en fin, planteamientos similares ${ }^{20}$.

Bien puede afirmarse, por todo ello, que la tesis del desplazamiento del principio de riesgo y ventura al de cobertura suficiente en la gestión del servicio no deja de ser una tesis que ni el legislador, ni la jurisprudencia, han terminado por sancionar en toda su plenitud.

\footnotetext{
${ }^{18}$ Es verdad que ese entendimiento del alcance del equilibrio económico-financiero frente al riesgo imprevisible no ha dejado de criticarse, básicamente porque, en ese caso, se trataba de una concesión local a la que era aplicable el Reglamento de Servicios de las Corporaciones Locales y éste parece garantizar la reparación íntegra del perjuicio [vid., por ejemplo, L. PAREJO ALFONSO en «¿Un paso atrás en la doctrina del riesgo imprevisible?», REDA, n. ${ }^{\circ} 18$ (1978), pp. 446 y ss.]; pero, en todo caso, el criterio de la Sentencia no deja de ser bien sintomático de las dudas que han planeado sobre esta fundamental cuestión, sin que en la actualidad se hayan superado.
}

19 Por todas, en la STS de 14 de marzo de 1985 se afirma que «la compensación económica no puede convertirse en una garantía a posteriori de los beneficios de la empresa, ni la subvención puede alcanzar el íntegro resarcimiento de los beneficios dejados de obtener, puesto que el restablecimiento económico visa a pasados ejercicios y con ello se pretende salvar la situación financiera de la concesionaria, por lo que en manera alguna está probado en autos que las pérdidas fueran debidas a causas ajenas a la buena gestión de la empresa, ni del concesionario, de acuerdo con el art. 129.4 del Reglamento citado (de Servicios de las Corporaciones Locales) ni como seguro que cubra sus pérdidas, puede jugar a favor de la Administración, art. 127.2.2.b), sino como una técnica que tiene por fin último asegurar el mantenimiento del servicio público en circunstancias anormales (art. 127.1), por lo que no rige un sistema de compensación integral de pérdidas, que es lo que parece perseguir la actora en el presente supuesto, sino en un reparto de los perjuicios imprevisibles entre el concesionario y la Administración, a la vista de las circunstancias sobrevenidas en relación con las tenidas como básicas al tiempo de constituir la concesión...».

${ }^{20}$ Baste remitirse a las convincentes explicaciones de M. Rebollo PuIG, El enriquecimiento injusto de la Administración Pública, Madrid, Marcial Pons, 1995, pp. 136 ss., que recuerda expresamente cómo la justificación de la doctrina del riesgo imprevisible se ha situado mayoritariamente en las exigencias del servicio público y no en la equidad, de manera que, en cuanto a sus efectos, de ninguna forma se ha considerado — singularmente en la doctrina francesa, que es de donde proviene básicamente la teorización que inspiró en gran medida las previsiones del Reglamento de Serviciosque debían ser los de una indemnización integral, sino, más bien, los de una participación administrativa en las pérdidas para evitar o impedir la ruina del contratista, lo que, de no ser así, perjudicaría gravemente el funcionamiento del servicio público. 
Por otra parte, la apreciación por los órganos jurisdiccionales de las circunstancias sobrevenidas e imprevisibles tiende a ser muy restrictiva. La STS de 23 de septiembre de 1981 (ar. 5295), entre otras más, es un buen ejemplo de lo que se afirma. Dice así:

«... el aumento de los costes salariales y el decrecimiento progresivo de la afluencia de viajeros que, si bien son circunstancias sobrevenidas independientes de la mala gestión [...], en cuanto que esas circunstancias son tendencias económico-sociales generalizadas y perfectamente conocidas que toda empresa debe precaver adoptando aquellas medidas de reestructuración que la más elemental técnica empresarial exige, siendo evidente que al haberse mantenido la asociación en la más absoluta pasividad ante dichas circunstancias incidió en una falta de previsión únicamente a ella imputable y que, en definitiva, el desequilibrio económico se reconduce a esa mala gestión e ineficacia que es consecuencia inevitable de su estructura organizativa, totalmente inadecuada...».

Fácilmente se comprende, pues, que, al igual que la repercusión económica que para la concesión provoca el decrecimiento del número de usuarios, no determina necesariamente que hayan de revisarse al alza las tarifas o que la Administración tenga que compensar las pérdidas de beneficio o los déficit que aquella circunstancia determina - y ello porque, salvo que la continuidad misma de la prestación del servicio corra serio peligro de poderse mantener, rige el principio de riesgo y ventura del concesionario-, tampoco el aumento de los gastos resultante de la supresión, en virtud de ley, de una exención fiscal cabe considerarlo como una circunstancia que automáticamente obligue a la Administración a restablecer el equilibrio ${ }^{21}$.

Así pues, las causas determinantes de la quiebra del equilibrio económico-financiero de la concesión condicionan el alcance de las consecuencias indemnizatorias que, a fin de restablecer el equilibrio, debe asumir la Administración. La STS de 14 de marzo de 1985 (ar. 1592) ya resumió magníficamente la cuestión y fijó en sus justos términos la operatividad de los principios de riesgo y ventura y de cobertura suficiente:

«Que el estudio de la situación doctrinal y jurisprudencial que se deja expuesta y de las diversas ideas y criterios en la misma se entrecruzan, conduce a estimar que la más matizada, progresista y aceptada construcción conceptual de la teoría del riesgo imprevisible es la que distingue entre el desequilibrio producido por la

\footnotetext{
${ }^{21}$ Téngase presente que, si así fuese, la garantía plena que desplaza al riesgo empresarial tendría que condicionar también el beneficio; un beneficio controlado que, a la postre, supondría la transformación de la propia técnica concesional. Como ha advertido recientemente A. RuIz OJEDA, $L a$ participación del sector privado en la financiación de infraestructuras y equipamientos públicos: Francia, Reino Unido y España, Madrid, Civitas, 2000, p. 256, «no hay alternativa: o se mantiene, con las atenuaciones que sean procedentes, la asignación del riesgo comercial al concesionario, o la concesión termina por convertirse en un engendro irreconocible».
} 
potestad variandi, el hecho del príncipe y el error de cálculo como causas que imponen a la Administración el deber de indemnizar al contratista tanto el daño emergente como el lucro cesante, lo cual supone restituir la retribución del concesionario a las condiciones inicialmente pactadas en atención al coste del establecimiento, los gastos de explotación y el beneficio industrial que determinaron en su momento inicial dicha retribución, y el desequilibrio producido por causas sobrevenidas e imprevisibles ajenas a la conducta de las partes, que ponen en peligro la supervivencia del servicio público por ruptura de la economía de la concesión, en cuyo caso la compensación debida al concesionario debe ir dirigida al mantenimiento del servicio mediante la distribución proporcional y razonable de las pérdidas entre ambos contratantes, de tal modo que la cuantía de la compensación no sea tan escasa que la haga ineficaz para impedir la ruina de la concesión, ni sea tan excesiva que desplace el riesgo normal de la empresa a la Administración concedente, imponiendo a ésta en favor del concesionario un auténtico seguro de beneficios mínimos o un resarcimiento de todos los perjuicios sufridos; compensación que por tanto no puede determinarse en atención a los elementos de la retribución pactada, sino mediante una apreciación global de las circunstancias concurrentes en cada caso a fin de conseguir la más adecuada y equitativa redistribución de la carga extracontractual, lo cual sólo es posible con base en informes periciales prudente y racionalmente valorados por el juzgador.»

Por último, no puede desconocerse que, en la medida en que se haya previsto a favor de la Administración concedente un canon concesional y ese canon se haya fijado en un porcentaje de los beneficios líquidos obtenidos al año por la explotación del servicio - como suele ser habitual, por ejemplo, en el caso concreto de las estaciones de autobuses-, la reducción del beneficio líquido por aumentar los gastos — en concreto, por razón del pago del impuesto dada la supresión de la exención - necesariamente repercutirá en el importe de ese canon, lo que, siquiera sea muy matizadamente, desde una estricta perspectiva jurídica también modulará el impacto de la modificación legal en la economía de la concesión. 
REAL-2001, núm. 286-287. FERNÁNDEZ FARRERES, GERMÁN. CONCESIONES DE SERVICIO PÚB...

REAL-2001, núm. 286-287. FERNÁNDEZ FARRERES, GERMÁN. CONCESIONES DE SERVICIO PÚB... 